\title{
MÉTODOS DE LAVAGEM DE FOLHAS DE MANGUEIRA PULVERIZADAS COM ZINCO
}

\author{
Diego Wyllyam do Vale, Renato de Mello Prado, Henrrique Antunes de Souza \\ e Mariana Marotti Corradi
}

Faculdade de Ciências Agrárias e Veterinárias de Jaboticabal, Departamento de Solos e Adubos, Via de Acesso, Prof. Paulo Donato Castellane, s/n, CEP 14884-900 Jaboticabal, SP, diegodwv@yahoo.com.br

\section{RESUMO}

Para frutíferas a aplicação de nutrientes via foliar visando a correção de deficiências nutricionais é muito usual. Todavia, se as folhas destinadas a análise química foliar não forem lavadas com solução de detergente e ácido clorídrico, poderão apresentar contaminante, mascarando os resultados. Este trabalho avalia os efeitos da lavagem sob diferentes concentrações de detergente e ácido nos teores de zinco em pomar de mangueiras pulverizadas com esse micronutriente.

Palavras-chave: Mangifera indica, teor de $\mathrm{Zn}$, lavagem de folhas

\section{WASHING METHODS OF ZINC SPRAYED MANGO LEAVES}

\begin{abstract}
Nutrients are sprayed on the leaves to correct nutritional deficiencies of fruit crops. However, when dealing with leaf chemical analysis one has to wash the leaves with a detergent and chloridric acid solution. This paper evaluates the effect of washing leaves using different concentrations of detergent and acid on the zinc contents in a mango orchard previously sprayed with this micronutrient .
\end{abstract}

Key words: Mangifera indica, zinc contents, leaf washing

\section{INTRODUÇÃO}

O zinco é um micronutriente de importância na produção de muitas espécies. Segundo Malavolta (1980), o zinco é fundamental para a síntese do triptofano, pois é o percussor do AIA, E os sintomas de deficiência são: encurtamento dos internódios e produção de folhas novas pequenas, cloróticas e lanceoladas. A concentração ótima de $\mathrm{Zn}$, de acordo com as espécies, varia de 20 a $1290 \mathrm{mg} / \mathrm{kg}$ na matéria seca das plantas (Faquin, 2005). Para Bennett (1998) o nível suficiente de Zn, de modo geral para as culturas, varia de 20 a $100 \mathrm{mg} / \mathrm{kg}$.

Aplicação de zinco no campo, principalmente via foliar, para correções de deficiências é prática comum no campo devido a agilidade na correção da deficiência e utilização, pelas plantas, dos nutrientes aplicados nas folhas; correção de algumas deficiências de micronutrientes em curto prazo de tempo; possibilidade da aplicação 
de micronutrientes juntamente com os defensivos agrícolas. Segundo Quaggio et al. (2003), a aplicação via foliar de $\mathrm{Zn}$ na laranjeira Pêra é mais eficiente do que a aplicação no solo. Canesin \& Buzetti (2007) afirmam que o sulfato de zinco + produtos quelatizantes são eficientes no aumento dos teores foliares de $\mathrm{Zn}$.

Aplicações foliares com zinco podem contaminar as amostras com o micronutriente e interferir no diagnóstico do estado nutricional da cultura.

Peryea (2005) observou que o uso da lavagem das folhas de macieira submetidas à aplicação de fertilizantes com zinco diminuiu a concentração do nutriente foliar comparado às amostras não lavadas. Assim, o uso de solução com detergente e ácido clorídrico, poderá eliminar grande quantidade do zinco foliar, em plantas submetidas à pulverização com o dado nutriente (Chamel et al., 1982). Por outro lado, a intensidade das lavagens das folhas e a concentração do detergente e do ácido clorídrico poderão afetar a eficiência da descontaminação das folhas. Salienta-se que a lavagem adequada das folhas deverá eliminar apenas os resíduos de $\mathrm{Zn}$ da superfície foliar, não interferindo nos nutrientes já absorvidos.

Segundo Varennes (2003), os fundamentos para a lavagem de folhas se apoiam em reduzir a contaminação superficial do material vegetal provocado pelo pó e pelo solo, que poderão alterar a concentração dos nutrientes quando da sua quantificação, especialmente os micronutrientes, todavia na literatura existem poucos trabalhos sobre o preparo e os cuidados necessários para lavagem de tecido vegetal são escassos.

Deste modo, o objetivo deste trabalho foi avaliar os efeitos da lavagem sob diferentes concentrações de detergente e ácido nos teores de zinco em pomar de mangueiras pulverizadas com esse micronutriente.

\section{MATERIAL E MÉTODOS}

O trabalho foi desenvolvido no Departamento de Solos e Adubos, realizando pulverização com sulfato de zinco em folhas de mangueiras da variedade Tommy Atkins no pomar da Fazenda Experimental da FCAV/UNESP, com uma solução contendo $3 \mathrm{~g}$ de sulfato de zinco por litro de água (Raij, 1997). Após sete dias da aplicação, realizou-se amostragem das folhas (10 folhas por parcela) de acordo com os tratamentos empregados. Utilizou-se um delineamento inteiramente casualizado, com três repetições, em esquema fatorial $(2 \times 3+1)$.

Os tratamentos foram constituídos por quantidade de lavagens (uma e duas), três concentrações de detergente $(0 ; 1,0$ e 2,0 $\mathrm{mL} / \mathrm{L})$ e ácido cloridrico $(0 ; 3,5$ e $7,0 \mathrm{~mL} / \mathrm{L})$ segundo Prado (2008) além da testemunha (sem lavagem e concentração de detergente+ácido).

Assim os tratamentos foram: T1 uma lavagem com imersão das folhas em água "pura" deionizada; T2 - uma lavagem com imersão das folhas utilizando apenas uma vez a dose padrão: detergente a 1,0 $\mathrm{mL} / \mathrm{L}$ e ácido clorídrico a $3,5 \mathrm{~mL} / \mathrm{L}$; T3 uma lavagem com imersão das folhas utilizando apenas duas vezes a dose padrão: detergente a $2,0 \mathrm{~mL} / \mathrm{L}$ e ácido clorídrico a 7,0 mL/L; T4 - duas lavagens com imersão das folhas em água "pura" deionizada; T5 duas lavagens com imersão das folhas utilizando apenas uma vez a dose padrão: detergente a $1,0 \mathrm{~mL} / \mathrm{L}$ e ácido clorídrico a $3,5 \mathrm{~mL} / \mathrm{L}$; T6 - duas lavagens com imersão das folhas utilizando apenas duas vezes a dose padrão: detergente a $2,0 \mathrm{~mL} / \mathrm{L}$ e ácido clorídrico a 7,0 mL/L; T7 - testemunha: sem lavagem, deixando da mesma forma que foi coletada no campo.

Após a lavagem o material foi seco em estufa de circulação forçada de ar em temperaturas variando de 65 a $70^{\circ} \mathrm{C}$, até peso constante. A matéria seca das plantas foi pesada e moída para as determinações 
químicas dos teores $\mathrm{Zn}$ no tecido vegetal, seguindo a metodologia descrita por Bataglia et al. (1983).

Os dados foram submetidos à análise de variância pelo teste $\mathrm{F}$, e quando significativo o teste de comparação de médias pelo teste de Tukey.

\section{RESULTADOS E DISCUSSÃO}

Houve resultados significativos na comparação entre o controle e os demais tratamentos, sendo que a testemunha que não recebeu nenhum tipo de lavagem teve teor de $\mathrm{Zn}$ superior às amostras que receberam lavagem e passaram por detergente e ácido, mostrando desta forma que há superestimação nos valores quando não se realiza nenhum tipo de lavagem nas folhas de mangueira (Tabela 1), corroborando afirmações feitas por Varennes (2003) que orienta o uso da lavagem de folhas para reduzir a contaminação superficial do material vegetal, em especial os micronutrientes.

Tabela 1. Teor de zinco em folhas de mangueira em função dos tratamentos com lavagem e do tratamento testemunha (sem lavagem)

\begin{tabular}{ll}
\hline Lavagem & $\mathbf{Z n}$ \\
\hline & $\mathrm{mg} / \mathrm{kg}$ \\
Com & $81,16^{*}$ \\
Sem & 583,33 \\
\hline
\end{tabular}

* Significativo pelo teste de $t$, ao nível de $5 \%$

Amostras de folhas coletadas no
pomar podem esconder problemas
nutricionais visualmente perceptíveis, mas
os resultados laboratoriais quando
comparados com tabelas padrões poderão
atestar valores sub ou superestimados do real
estado nutricional da cultura. Observa-se a
grande importância em se realizar a lavagem
das folhas, visto que esta prática permitiu
redução superior a $700 \%$ do teor de
nutrientes em folhas de mangueira se estas

não fossem submetidas a algum método de lavagem. Muitos laboratórios do Brasil recebem folhas com teores altíssimos de micronutrientes, pois é prática comum a aplicação destes, previsto em boletins de recomendação de adubação (Raij, 1997), ou ainda, podem ser oriundos de produtos fitossanitários utilizados na cultura para controle de pragas e de doenças.

A prática da aplicação de zinco via foliar se mostrou eficiente para a cultura da mangueira e proporcionou teores considerados como consumo de luxo (Fernandes \& Nascimento, 2004) para folhas que foram lavadas e extremamente tóxicos para aquelas folhas que não foram submetidas a nenhum método de lavagem foliar.

Para o desdobramento de lavagens com concentração de detergente e ácido, a interação foi significativa, sendo que quando se realiza duas lavagens das folhas o uso de ácido é imprescindível para determinação do real estado nutricional da cultura, observando que o ácido foi importante para reduzir o $\mathrm{Zn}$ adsorvido à superfície da folha em cerca de $30 \%$ (Tabela 2).

Tabela 2. Teor de zinco $\left(\mathrm{mg} \mathrm{kg}^{-1}\right)$ de folhas de mangueira em função da quantidade de lavagens e concentrações de detergente/ácido $\left(\mathrm{ml} \mathrm{L}^{-1}\right)$

Concentração detergente/ácido

\begin{tabular}{crcc} 
Lavagem & $\mathbf{0 , 0 / 0 , 0}$ & $\mathbf{1 , 0 / 3 , 5}$ & $\mathbf{2 , 0 / 7 , 0}$ \\
\hline $\mathbf{1}$ & $104 \mathrm{Ab}^{*}$ & $76 \mathrm{Aa}$ & $74 \mathrm{Aa}$ \\
$\mathbf{2}$ & $87 \mathrm{Aa}$ & $68 \mathrm{Ba}$ & $76 \mathrm{Ba}$
\end{tabular}

* As médias seguidas pela mesma letra minúscula na coluna e maiúscula na linha não diferem entre si pelo teste de Scott-Knott

O uso de doses de detergente e ácido acima das concentrações recomendadas não é necessário para remoção do $\mathrm{Zn}$ adsorvido à superfície das folhas, verificando que as concentrações $1 \mathrm{~mL} / \mathrm{L}$ e $3,5 \mathrm{~mL} / \mathrm{L}$ não apresentaram diferença significativa no teor 
de $\mathrm{Zn}$ no tratamento que recebeu maiores concentrações de detergente e ácido.

Observou-se menor teor de $\mathrm{Zn}$ quando se realizou duas lavagens das folhas em água, se comparado ao tratamento em que se realizou apenas uma lavagem em água, apesar de não ter sido significativo para a concentração de ácido/detergente de 1,0/3,5 (Tabela 2).

Os resultados mostram a importância de se utilizar o detergente e o ácido nas lavagens de folhas de mangueira, sendo que independe da quantidade de lavagens e a concentração de detergente e ácido, justificando afirmações de Varennes (2003) que relata que os fundamentos para a lavagem de folhas se apoiam em reduzir a contaminação superficial do material vegetal provocado por agentes contaminantes como terra e defensivos, que poderão alterar a concentração dos nutrientes quando da sua quantificação, especialmente os micronutrientes. Corroborando os resultados obtidos por Peryea (2005) de que o uso da lavagem das folhas de macieira submetidas à aplicação de fertilizantes com zinco diminuiu a concentração do nutriente foliar comparado a amostras não lavadas.

Por facilidade de manuseio da amostra, uma lavagem seria suficiente para diminuição de possíveis erros provenientes de contaminantes. A utilização de detergente mais ácido se faz fundamental para garantir amostra mais pura para futura análise. Dessa maneira os laboratórios de análises poderiam otimizar o preparo das amostras com apenas uma lavagem e também reduzir o custo de produtos químicos usando menos detergente e ácido.

Conforme observações feitas por Fontes (2001) contaminantes na amostra podem ser fonte significativa de erros na análise química, principalmente de micronutrientes, devendo ser eliminados dos tecidos, evidências estas que foram comprovadas neste trabalho, pois sem o uso da lavagem das folhas a concentração de zinco foi muito elevada, corroborando os resultados obtidos por Wyttenbach \& Toubler (1998).

Chamel et al. (1982) afirmaram que o uso de solução com detergente e ácido clorídrico, pode eliminar grande quantidade do zinco foliar, em plantas submetidas à pulverização com o dado nutriente, confirmando a necessidade da lavagem das folhas em solução com detergente e ácido clorídrico para eliminação dos contaminantes foliares.

Mills \& Jones (1996) relataram que a descontaminação será essencial se forem determinados os teores de ferro e alumínio, no entanto, conforme resultados obtidos neste trabalho, verificam-se que para determinação de zinco também é imprescindível a prática de lavagem das folhas.

Sonneveld \& Dijk (1982) citaram que para eficiente descontaminação do material é necessário que as amostras sejam rapidamente lavadas em solução 0,1 a $0,3 \%$ de detergente, esfregando-se levemente 0 dedo sobre o tecido, enxaguando-o com água deionizada, metodologia esta que se mostrou eficiente no presente trabalho para descontaminação de zinco em amostras foliares de mangueiras.

Os teores considerados adequados para zinco em mangueira são variáveis, sendo de $90 \mathrm{mg} / \mathrm{kg}$ (Malavolta et al., 1997) a 20-40mg/kg (Raij et al., 1997).

Segundo Nascimento et al. (2008) a adubação foliar tem sido freqüentemente, empregada em frutíferas, especialmente para os micronutrientes, embora não exista recomendação específica de micronutrientes para mangueira em produção, fundamentada em experimentação; os mesmos autores citam que dentre os micronutrientes o Zn é um dos que apresentam maiores problemas, principalmente em frutíferas. 


\section{CONCLUSÕES}

O preparo da amostra com lavagem das folhas com água deionizada e com produtos químicos proporcionou descontaminação da amostra que recebeu a pulverização com micronutriente zinco.

A lavagem do material vegetal por duas vezes em água deionizada, juntamente com a utilização de $1 \mathrm{~mL} / \mathrm{L}$ de detergente + 3,5 $\mathrm{mL} / \mathrm{L}$ de ácido é uma opção para proporcionar menor teor de zinco nas folhas de mangueira pulverizadas com esse micronutriente.

\section{REFERÊNCIAS BIBLIOGRÁFICAS}

BATAGLIA, O.C.; FURLANI, A.M.C.; TEIXEIRA, J.P.F.; FURLANI, P.R.; GALLO, J.R. Métodos de análise química de plantas. Campinas: Instituto Agronômico, 1983. 48p. (Boletim Técnico, 78).

BENNETT, W. F. Plant nutrient utilization and diagnostic plant symptoms. In: BENNETT, F. W. Nutrient deficiencies \& toxicities in crop plants. Sainte Paul: APS Press, 1998. p. 1-7.

CANESIN, R. C. F. S. \& BUZETTI, S. Efeito da aplicação foliar de boro e zinco sobre a produção e os teores de SST e ATT dos frutos da PereiraJaponesa e da pinheira. Revista Brasileira de Fruticultura, v. 29, p. 377-381, 2007.

CHAMEL, A.R., MARCELLE, R.D., ELOY, J.F. Cuticular retention in vitro and localization of $\mathrm{Zn}$ after a foliar application of zinc-containing fungicides. Journal of American Society for Horticultural Science, v.107, p.804-807, 1982.

FAQUIN, V. Nutrição mineral de plantas. Lavras: UFLA/FAEPE, 2005. 183 p.
FERNANDES, F. M. \& NASCIMENTO, V. M. Fertilidade do solo e nutrição da mangueira. In: ROZANE, D. E.; DAREZZO, J. D.; AGUIAR, R. L.; AGUILERA, G. H. A.; ZAMBOLIM, L. Manga produção integrada, industrialização e comercialização. Viçosa: UFV, 2004. p.179-198.

FONTES, P.C.R. Diagnóstico do estado nutricional das plantas. Viçosa: UFV, 2001. p.34-40.

QUAGGIO, J. A.; MATTOS JÚNIOR, D.; CANTARELLA, H.; TANK JÚNIOR, A. Fertilização com boro e zinco no solo em complementação à aplicação via foliar em laranjeira Pêra. Pesquisa Agropecuária Brasileira, v. $38, \mathrm{P}$. 627-634, 2003.

MALAVOLTA, E. Avaliação do estado nutricional das plantas: princípios e aplicações. Piracicaba: Potafós, 1997. p. 135-198.

MALAVOLTA, E. Elementos na nutrição mineral de plantas. São Paulo: Agronômica/Ceres, 1980. 251 p.

MILLS, H. A. \& JONES JR., J.B. Plant analysis handbook II. Georgia, USA: Micromacro Publishing, 1996. 422p.

NASCIMENTO, V. M.; FERNANDES, F. M.; PRADO, R. M; CORREAA, L. S.; NATALE, W. Adubação da mangueira: alternativa para alta produção. Ilha Solteira: FE, 2008. 107 p.

PERYEA, F. J. Sample washing procedures influence mineral element concentrations in zinc sprayed apple leaves. Communications in Soil Science and Plant Analysis, v.36, p.2923-2931, 2005.

PRADO, R.M. Manual de nutrição de plantas forrageiras. Jaboticabal: FUNESP, 2008. 500 p.

RAIJ, B.van.; CANTARELLA, H.; QUAGGIO, J.A.; FURLANI, A.M.C. Recomendações de adubação e calagem para o estado de São Paulo. $2^{\mathrm{a}}$ ed. 
Campinas: Instituto Agronômico, 1997. p.233-239.(Boletim técnico, 100).

SNNEVELD, C. \& DIJK, P.A. van. The effectiveness of some washing procedures on the removal of contaminants from plant tissue samples of grasshouse crops. Communication Soil Science Plant Analysis, v.13, p.487-496, 1982.
VARENNES, A. Produtividade do solo e ambiente. Lisboa: ISA, 2003. 490 p.

WYTTENBACH, A. \& TOBLER, L. Effect of surface contamination on results of plant analysis. Communication Soil Science Plant Analisys, v.29, p.809823, 1998. 